\title{
ANATOMIA ECOLÓGICA DA FOLHA DE Eugenia glazioviana KIAERSK (MYRTACEAE) ${ }^{1}$
}

\author{
Natalia Pimentel Esposito-Polesi², Ricardo Ribeiro Rodrigues² e Marcílio de Almeida ${ }^{4}$
}

\begin{abstract}
RESUMO - Dos mecanismos com potencial valor adaptativo em resposta ao estresse hídrico merece destaque o apresentado por Eugenia glazioviana Kiaersk cuja perda de turgescência foliar e consequente curvatura do limbo da posição horizontal para a vertical, sem a abscisão das folhas, que estão associados à redução da superfície foliar exposta à luz solar. Dessa forma, o presente trabalho teve por objetivo a caracterização histológica da folha da espécie, visando compreender melhor esse mecanismo de resposta ao estresse hídrico. Para tanto foram realizados cortes transversais e paradérmicos da lâmina foliar, bem como, cortes transversais do pecíolo, sendo estes analisados e as imagens capturadas em microscópio de luz. Os resultados permitem, entre outras coisas, afirmar que E. glazioviania possui características tipicamente xerofíticas, sendo elas: cutícula espessa em ambas as superfícies, folha hipoestomática, com muitos tricomas tectores na face abaxial, além de uma característica que pode ser exclusiva da espécie e que possivelmente justifique tal resposta, a qual relaciona-se a presença de ductos glandulares, que percorrem toda a extensão do pecíolo, em continuidade com a lâmina foliar.
\end{abstract}

Palavras-chave: Estresse, Resposta, Xerófita e Ductos glandulares.

\section{ECOLOGICAL ANATOMY OF Eugenia glazioviana KIAERSK LEAF (MYRTACEAE)}

\begin{abstract}
In response to hydrous stress, the adaptive mechanisms with a potential adaptive value presented by Eugenia glazioviana Kiaersk is notable, whose leaf turgidity loss and the blade consequent curvature from the horizontal to vertical position, without the leaves abscission, are associated with the reduction of the leaf surface exposed to sunlight. This study aimed to characterize histological leaf species to better understand the mechanism in response to hidrous stress. Therefore, we performed transverse and paradermal cuts from the leaf blade and petiole cross-sections. They were analyzed and the images were captured under light microscope. Among other things, the results allowed to state that E. glazioviana has typically xerophytic characteristics, namely: "thick cuticle on both surfaces, hypostomatic leaves with many trichomes on the abaxial side", and a characteristic that may be unique to that species and possibly justify such response, which is related to the glandular ducts presence, running the petiole length in continuity with the leaf blade.
\end{abstract}

Keywords: Stress, Response, Xerophytic and Glandular ducts

\section{INTRODUÇÃO}

A Eugenia glazioviana Kiaersk, espécie presente no remanescente de Floresta Estacional Decidual, no Município de Piracicaba, SP, responde de maneira diferenciada às condições de estresse hídrico, se comparada às demais espécies presentes nesse fragmento, que são decíduas (IVANAUSKAS e RODRIGUES, 2000). Tais florestas apresentam condições ambientais extremas: solos férteis com baixa retenção hídrica, fatores que acabam selecionando espécies mais aptas a se estabelecerem nesses ambientes (SILVA e SCARIOT, 2003).

\footnotetext{
${ }^{1}$ Recebido em 16.07.2008 e aceito para publicação em 16.12.2010.

${ }^{2}$ Universidade de São Paulo, USP, Brasil. E-mail: <natalia.polesi@yahoo.com.br>.

${ }^{3}$ Departamento de Ciências Biológicas da ESALQ/USP, São Paulo, Brasil. E-mail: <rrr@esalq.usp.br>.

${ }^{4}$ Departamento de Ciências Biológicas da ESALQ/USP, Laboratório de Morfogênese e Biologia Reprodutiva de Planta, São Paulo, Brasil.E-mail: <malmeida@esalq.usp.br>.
} 
As plantas durante seu ciclo de vida nem sempre encontram condições ambientais onde todos os fatores sejam favoráveis ao seu crescimento e desenvolvimento, estabelecendo o estresse (CHAVES FILHO e STACCIARINI-SERAPHIN, 2001). O termo estresse é utilizado pela maioria dos autores em sentido muito amplo, e isso ocorre porque a planta não possui muitas possibilidades de respostas, ou seja, independentemente dos fatores de estresse, a resposta é igual ou muito semelhante (LICHTENTHALER, 1996).

Importante fator ambiental de estresse é a redução na disponibilidade de água do solo, que ocorre geralmente de maneira gradual na natureza (CHAVES FILHO e STACCIARINI-SERAPHIN, 2001). Diferentes espécies têm desenvolvido muitos mecanismos para sobreviverem à restrição hídrica no solo, evitando-a ou tolerando-a (LAMBERS et al., 1998), através de modificações morfológicas, histológicas, citológicas e fisiológicas (DICKISON, 2000). Tais mecanismos permitem classificar as plantas em três categorias principais: a) espécies que escapam da seca (rápido desenvolvimento fenológico), b) espécies que toleram a seca com alto potencial hídrico (evitam a desidratação) e c) espécies que toleram a seca com baixo potencial hídrico (toleram a desidratação) (TURNER, 1997; VERSLUES et al., 2006).

Segundo Taiz e Zeiger (2004), uma das estratégias de resistência ao estresse hídrico é a abscisão foliar, caracterizada pela senescência das folhas, podendo ocorrer essa abscisão mais de uma vez numa única estação. Tal estratégia é verificada na maioria (59\%) das espécies presentes nessa formação, apresentando mecanismos adaptativos fisiológicos e, ou, morfológicos em resposta à deficiência hídrica estacional, armazenando água, perdendo as folhas, absorvendo a umidade atmosférica, através de órgãos especializados, entre outros (IVANAUSKAS e RODRIGUES, 2000).

A Eugenia glazioviana, no entanto, caracteriza-se por responder diferentemente às condições de estresse hídrico, em comparação com as demais espécies, apresentando perda de turgescência foliar e posterior curvatura da folha, da posição horizontal para a vertical (Figura 1), o que resulta em menor exposição ao sol e a fatores que catalisam o processo de perda de água. Quando o suprimento hídrico se restabelece, a folha recupera a turgescência e volta à posição horizontal.

Tais mecanismos de resposta ao estresse hídrico podem ser entendidos se se recorrer ao conceito de plasticidade fenotípica. Tanto para plantas quanto para animais, há claras evidências de que o desenvolvimento de alterações nas características funcionais e estruturais dos indivíduos está associado aos fatores ambientais a que estão expostos (GRIME e MACKEY, 2002). Dessa forma, plasticidade fenotípica define-se como a habilidade do indivíduo em responder com mudanças em seu fenótipo a diferentes condições ambientais. As espécies com grande potencial para plasticidade em caracteres ligados à sobrevivência apresentam vantagens adaptativas em ambientes instáveis, heterogêneos ou de transição, visto que as mudanças produzidas podem facilitar a exploração de novos nichos, resultando no aumento da tolerância ambiental (VIA, 1993; VIA et al., 1995).

Alterações na anatomia da folha constituem aspectos decisivos na capacidade de aclimatação das espécies expostas a diferentes condições de ambiente (HANBA et al., 2002; SCHLUTER et al., 2003). As adaptadas a ambientes secos (plantas xeromorfas), por exemplo, apresentam como características morfoanatômicas: estômatos em depressões na superfície da epiderme, numerosos tricomas, cutícula grossa, presença de hipoderme, parênquima incolor, grande quantidade de esclerênquima, células com paredes espessadas e lignificadas, além da redução na espessura do mesofilo e da lâmina foliar, que pode ser decorrente de redução no número de estratos celulares ou de diminuição dos espaços intercelulares (CHARTZOULAKIS et al., 2002; MENEZES, 2003; ELIAS et al., 2003).

Como a lâmina foliar é a estrutura que mais se modifica em resposta às alterações ambientais e constitui o principal sítio na produção de fotoassimilados, a anatomia foliar vem sendo objeto de estudo de vários trabalhos (ELIAS et al., 2003). Por essa razão, esta pesquisa teve por objetivo realizar estudo histológico da folha de Eugenia glazioviana Kiaersk, visando gerar informações úteis para se compreender melhor o valor adaptativo das respostas morfoanatômicas às condições naturais de ocorrência dessa espécie, bem como servir de modelo para as demais espécies.

\section{MATERIAL E MÉTODOS}

O material vegetal consistiu de folhas completamente expandidas do primeiro, segundo e terceiro nós de ramos adultos de Eugenia glazioviana, presentes no remanescente da floresta estacional decidual, no Bairro de Godinhos, em Piracicaba, SP (22 43'30' ' S, 47³8' W - 554 m de altitude). Parte desse material foi incluso no Herbário ESA (Herbário da ESALQ) e identificado pela Dra. Fiorella Fernanda Mazine Capelo, especialista no gênero. 

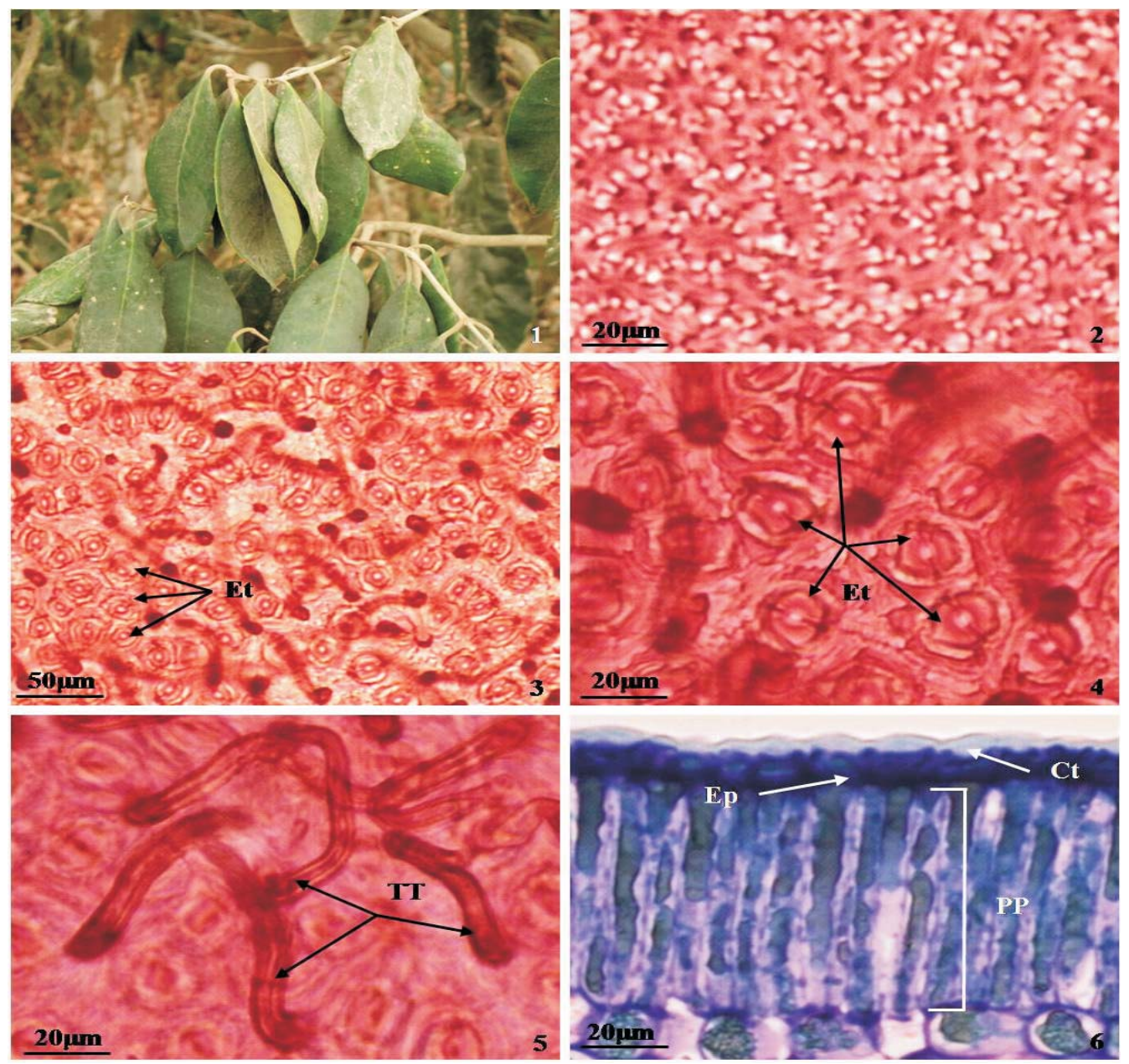

Figuras 1 - 6. Eugenia glazioviana - Folhas e secções da Lâmina Foliar. 1. Curvatura da folha do sentido horizontal para o vertical. 2. Secção paradérmica da face adaxial evidenciando o contorno sinuoso das células epidérmicas. 3 - 5. Secções paradérmicas da face abaxial com elevado número de estômatos e de tricomas tectores. 6 . Secção transversal que evidencia a epiderme adaxial formada por uma camada de células com cutícula espessa e parênquima clorofiliano paliçádico constituído de uma camada de células. Abreviaturas: Et - estômato, TT - tricoma tector, Ct - cutícula, Ep - epiderme, PP - parênquima paliçádico.

Figures 1 - 6. Eugênia glazioviana - Leaf and cross sections of leaf blade. 1. Blade curvature from the horizontal to the vertical position. 2. Paradermal section of the adaxial surface showing the epidermal cells outline sinuous. 35. Paradermal section of the abaxial surface with elevated number of stomata and tector trichomes. 6. Transversal section that shows the adaxial epidermis formed by a cells layer with thick cuticle and palisade chlorophyll parenchyma formed by a cells layer. Abbreviations: St - stomata, TT - tector trichomes, Ct - cuticle, Ep-epidermis, and PP - palisade parenchyma.

Partes da região basal e apical do pecíolo e das regiões basal, mediana e apical da lâmina foliar foram fixadas em solução de glutaraldeído e formaldeído (KARNOVSKY, 1965) por 48 h, seguido da desidratação etílica em série crescente, permanecendo em cada uma delas por 10 min e, por fim, incluídos em resina de hidroxietilmetacrilato (LEICA-HISTORESIN), de acordo com as recomendações do fabricante. Secções transversais, com $5 \mu \mathrm{m}$ de espessura, foram obtidas com o auxílio de micrótomo rotativo (E.LEITZ WETZLAR) e posteriormente coradas com azul de toluidina $(0,05 \%)$ em tampão-fosfato e ácido cítrico (SAKAI, 1973) e montadas em lâminas histológicas com resina sintética (Entellan ${ }^{\circledR}$ ).

Revista Árvore, Viçosa-MG, v.35, n.2, p.255-263, 2011 
Secções à mão-livre também foram realizadas em porções da região mediana da lâmina foliar. As secções foram clarificadas utilizando-se hipoclorito de sódio comercial 20\% (v/v), lavadas com água destilada e coradas com safranina $1 \%$ por $5 \mathrm{~min}$. Posteriormente, as secções paradérmicas de ambas as superfícies foram montadas em lâminas histológicas com solução de gelatina glicerinada, de acordo com Kaiser (1880 citado por KRAUS e ARDUIN, 1997) e Pereira et al. (2003).

Os cortes foram analisados em microscópio de luz (ZEISS-JENEMED2), com as imagens capturadas na mesma escala micrométrica com câmera SAMSUNG (SDC-313).

\section{RESULTADOS}

Em secção paradérmica da superfície adaxial da lâmina foliar, observou-se pouco ou nenhum tricoma tector. A epiderme é formada por células justapostas, isodiamétricas, apresentando contorno sinuoso e ausência de estômatos (Figura 2). Na epiderme da face abaxial em vista frontal, observa-se grande número de estômatos (Figuras 3 e 4), o que permite classificar a folha como hipoestomática. Os estômatos presentes na superfície abaxial variam quanto ao tipo em paracíticos, anomocíticos e anômalos (Figura 4), e sua elevada quantidade dificulta, sobremaneira, sua classificação, assim como a observação das células epidérmicas. A epiderme abaxial conta ainda com muitos tricomas tectores unicelulares (Figuras 4 e 5), de forma alongada e cilíndrica; não foram localizados tricomas glândulares, escamas ou qualquer outro anexo epidérmico comum a outras espécies de Eugênia.

A secção transversal da lâmina foliar mostra um único extrato de células epidérmicas fortemente unidas, sob uma camada de cutícula de aproximadamente $5 \mu \mathrm{m}$ de espessura na face adaxial (Figura 6) e $3 \mu \mathrm{m}$ de espessura na face abaxial (Figura 7). O mesofilo é dorsiventral, com parênquima clorofiliano paliçádico constituído por uma única camada de células alongadas no sentido perpendicular, variando em média de 50 a $60 \mu \mathrm{m}$ de altura (Figuras 6 e 8); e o parênquima clorofiliano lacunoso, logo abaixo, constituído por aproximadamente 10 camadas de células arredondadas, apresentando grandes espaços intercelulares (variando em média de 20 a $55 \mu \mathrm{m}$ de largura por 35 a $120 \mu \mathrm{m}$ de altura) (Figuras 7 e 9). Observou-se também a presença de ductos glandulares ao longo do mesofilo, circundados por células secretoras alongadas com paredes finas (Figura 10); além disso, o mesofilo apresenta idioblastos contendo drusas, possivelmente de oxalato de cálcio (Figura 7).

Os feixes vasculares, que aparecem entre as células do parênquima clorofiliano lacunoso, são do tipo colateral quando menos desenvolvidos (Figura 11), e os de maior porte são do tipo bicolateral (Figura 12), ambos com fibras de esclerênquima, que ocorrem, tanto do lado do xilema quanto do floema, provavelmente de origem pericíclica, que por sua vez são circundados por células com formato distinto das demais.

Em secção transversal do pecíolo (Figura 13), pode-se verificar a presença de uma camada de epiderme formada por células isodiamétricas sem espaços intercelulares e com elevado número de tricomas tectores unicelulares (Figura 14). Sob a epiderme, observa-se a presença de tecidos de sustentação (colênquima) alternados com o parênquima fundamental e grande quantidade de drusas na região cortical, e destaca-se, também, a presença de ductos glandulares (Figuras 14, 15 e 16), que percorrem toda a extensão do pecíolo, em continuidade com a lâmina foliar, com forma e diâmetro variados tendendo a fusionar-se longitudinalmente formando um único e longo canal em direção à base peciolar; além da presença de esclerênquima próximo aos feixes vasculares, que por sua vez são compostos por xilema, organizado em colunas aparentemente separadas por um septo fibroso (fibras esclerenquimáticas) nas extremidades, envolto por duas camadas de floema (bicolateral) (Figuras 17 e 18).

\section{DISCUSSÃO}

A presença de células epidérmicas com contorno sinuoso observada em corte paradérmico também foi encontrada em Eugenia dysenterica (PALHARES, 2003) e em Eugenia brasiliensis (DONATO e MORRETES, 2007). Segundo Menezes (2003), tal sinuosidade ocorre em razão, provavelmente, das tensões ocorridas na folha e do endurecimento da cutícula durante a diferenciação das células.

Além disso, a folha hipoestomática com estômatos paracíticos e anomocíticos são características frequentemente encontradas em outras espécies da família Myrtaceae (PALHARES, 2003; DONATO e MORRETES, 2007; ALVES et al., 2008; GOMES et al., 2009). Dessa forma, a ausência de estômatos na face 

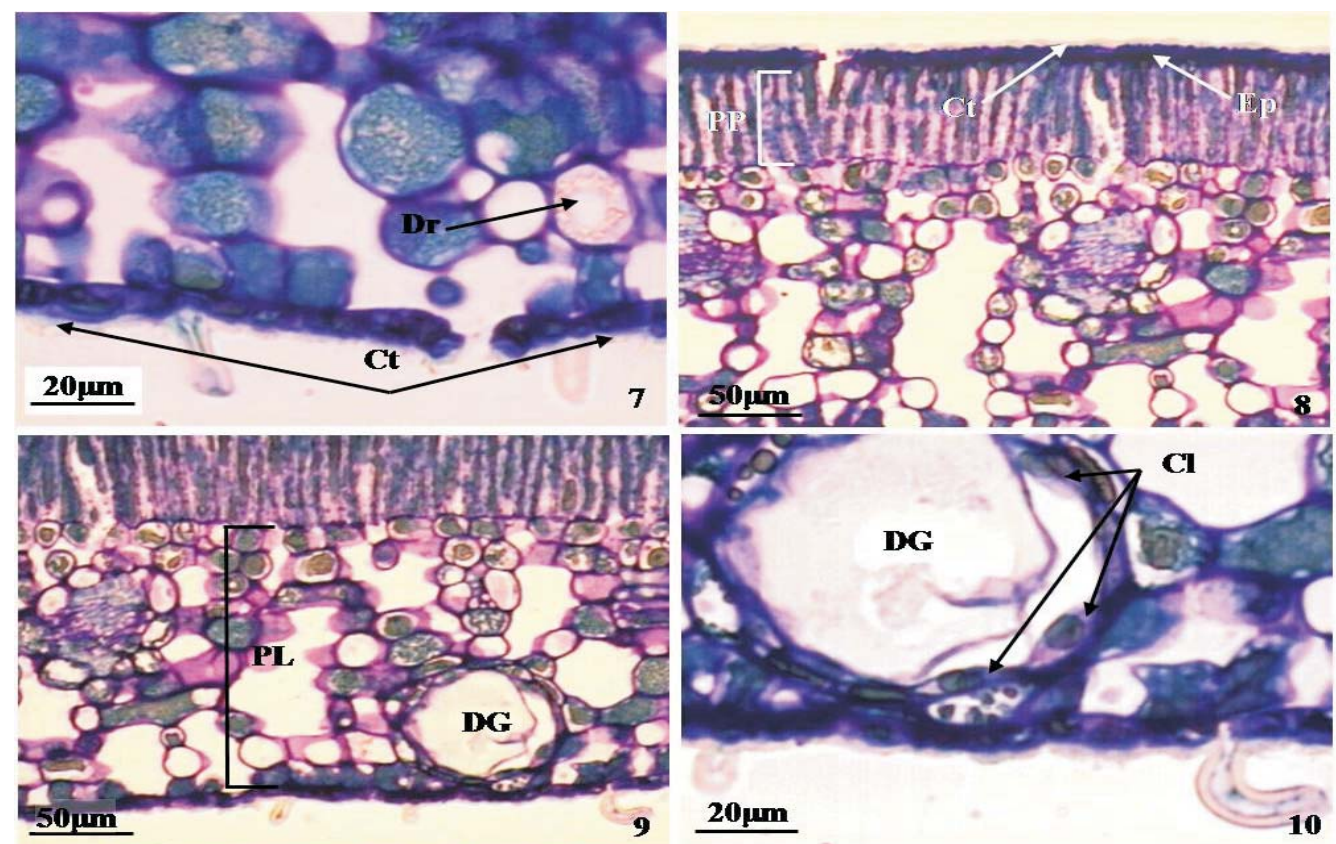

$\underline{20 \mu m}$

10
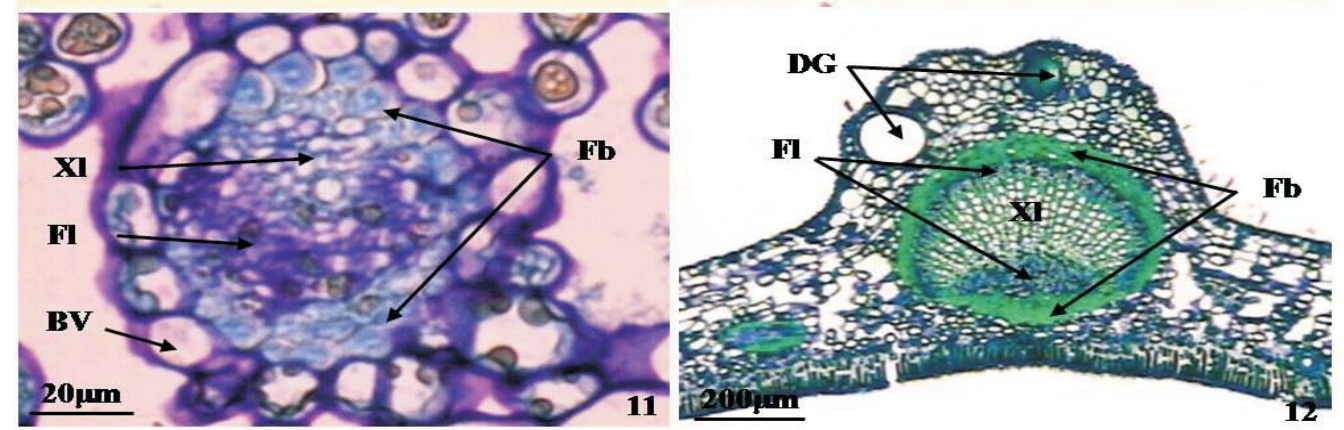

Figuras 7 - 12. Eugenia glazioviana - Secções Transversais da Lâmina Foliar. 7. Epiderme da face abaxial formada por uma camada de células com cutícula espessa, e presença de idioblastos com drusas. 8 e 9. Mesofilo dorsiventral formado por uma única camada de parênquima paliçadico, parênquima lacunoso, logo abaixo, constituído por células arredondadas. 10. Ducto glandular circundado por células alongadas de paredes delgadas. 11. Feixe vascular do tipo colateral quando menos desenvolvido. 12. Feixe vascular do tipo bicolateral na nervura mediana. Abreviaturas: Ct - cutícula, Dr - drusas, Ep - epiderme, PP - parênquima paliçádico, PL - parênquima lacunoso, DG - ducto glandular, $\mathrm{Cl}$ - células, $\mathrm{Xl}$ - xilema, $\mathrm{Fl}$ - floema, BV - bainha vascular, $\mathrm{Fb}$ - fibra esclerenquimática.

Figures 7 - 12. Eugênia glazioviana - Traversal sections of the leaf blade. 7. (sai The Epiderm) Epidermis of abaxial suface formed by a cells layer with thick cuticle and idioblasts with druses. 8 e 9. Dorsiventral mesophyll formed by a unique layer of the palisade parenchyma, spongy parenchyma at below, consisting of rounded cells. 10. Glandular ducts surrounded by prolonged cells of thin walls. 11. Collateral vascular bundle less developed. 12. Bi-side vascular bundle in midrib. Abbreviations: Ct - cuticle, Dr - druses, Ep - epiderm, PP - palisade parenchyma, SP - spongy parenchyma, GD - glandular duct, Cl - cells, Xl-xylem, Fl - phloem, VS - vascular sheath, and SF -sclerenchymatic fiber.

adaxial, característico de plantas xeromórficas, permite grande economia de água, por reduzir a taxa transpiratória, devido à menor exposição à luz solar. Segundo Kundu e Tigerstedt (1998), a distribuição dos estômatos na face abaxial pode representar proteção contra as condições microambientais, como temperatura mais elevada na face adaxial e o grau de umidade, que é maior na face abaxial. O elevado número de estômatos verificado em Eugenia glazioviana permite que a planta eleve a condutância de gases, evitando, assim, que 
a fotossíntese seja limitada sob diferentes condições de ambiente (LIMA et al., 2006), além de diminuir a transpiração, devido à formação de arcos de transpiração mais próximos entre si, o que retém maior umidade na área estomática (LARCHER, 2001).
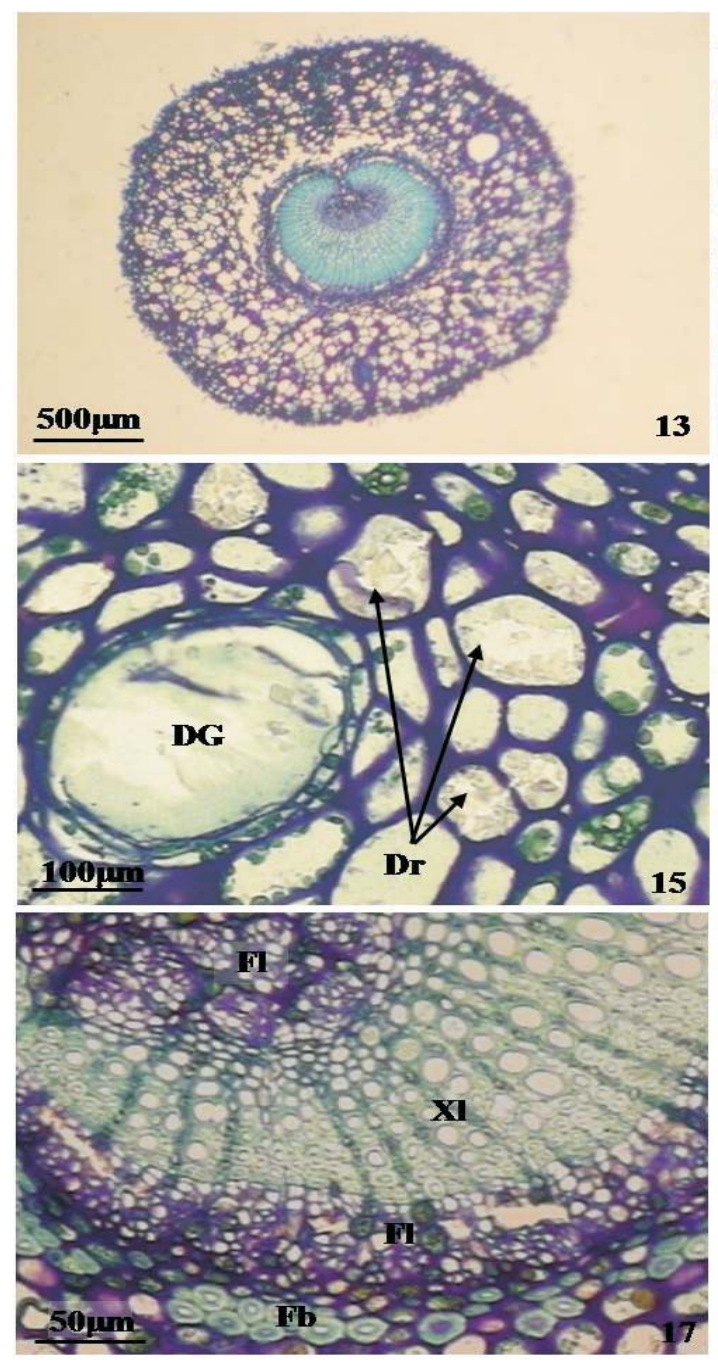

3
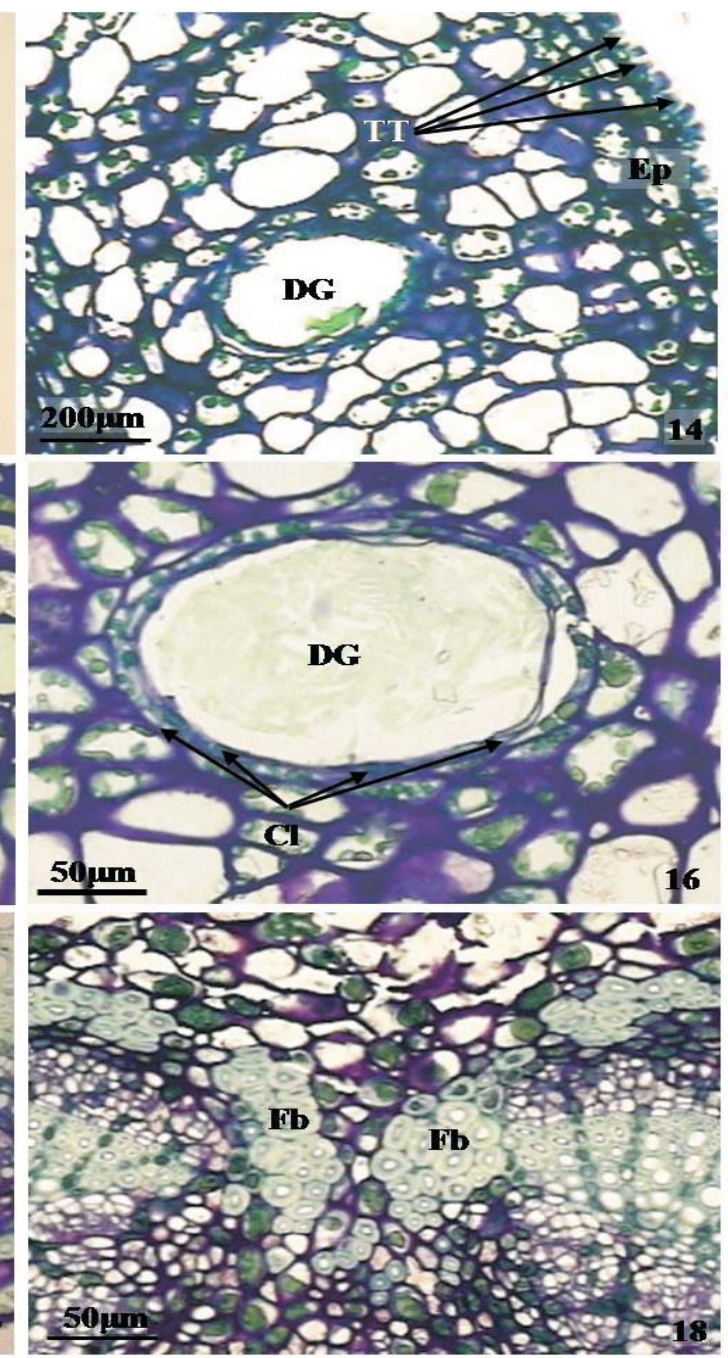

Figuras 13 - 18. Eugenia glazioviana - Secções transversais do pecíolo. 13. Modelo do cilindro vascular. 14. Epiderme com elevado número de tricomas tectores unicelulares, colênquima alternado com o parênquima fundamental, grande quantidade de drusas na região cortical e ductos glandulares. 15 e 16. Ducto glandular com forma e diâmetro variado, cincundado por células secretoras de paredes delgadas. 17 e 18. Feixe vascular bicolateral com xilema separado por um septo fibroso. Abreviaturas: TT - tricomas tectores, Ep - epiderme, DG - ducto glandular, $\mathrm{Dr}$ - drusas, $\mathrm{Cl}$ - células, $\mathrm{Xl}$ - xilema, $\mathrm{Fl}$ - floema, Fb - fibra esclerenquimática.

Figures 13-18. Traversal sections of petiole. 13. model of the vascular cylinder. 14. Epiderms with elevated number unicellular non-glandular trichomes, collenchyma alternated with the fundamental parenchyma, large amount of druses in the cortical region and glandular ducts.15 e 16. Glandular duct with varied shape and diameter, surrounded by secretory cells of thin walls. 17 e 18. Vascular bundles bicollateral with xylem separate of the schlerenchymatous fibers. Abbreviations: TT - non-glandular trichomes, Ep - epidermis, DG - glandular ducts, Dr. - druses, Cl - cells, Xl-xylem, Fl-phloem and Fb-fiber sclerenchymatic.

Revista Árvore, Viçosa-MG, v.35, n.2, p.255-263, 2011

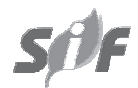


contra temperaturas extremas, alta intensidade luminosa, perda excessiva de água, entre outros fatores (WERKER, 2000). Os tricomas são estruturas importantes, pois mantêm atmosfera saturada em vapor de água em torno da folha. Além do efeito direto sobre a redução da transpiração, essas estruturas podem influenciar indiretamente na economia de água das plantas através da regulação da temperatura pela reflexão da radiação solar que chega até as folhas (LARCHER, 2001).

A presença de cutícula espessa em ambas as faces da folha, também característico de xerófitas, pode ser considerada prevenção contra a transpiração, pois a cutícula incrementa a espessura da folha e contribui com sua textura coriácea (LARCHER, 2001), podendo contribuir também para o desenvolvimento de ondulações nas células epidérmicas (PEREIRA et al., 2003).

O mesofilo dorsiventral constitui característica apomórfica na família Myrtaceae (GOMES et al., 2009). Já a quantidade de camadas de células no parênquima clorofiliano paliçádico é variável entre as espécies, sendo encontrado na literatura: uma camada (DONATO e MORRETES, 2007; ALVES et al., 2008; GOMES et al., 2009), duas camadas (PALHARES, 2003; GOMES et al., 2009) ou três camadas (GOMES et al., 2009). O parênquima clorofiliano lacunoso, por sua vez, tem variações ainda maiores de 3 a 15 camadas de células, dependendo da espécie, como verificado nos trabalhos com espécies da família Myrtaceae (PALHARES, 2003; DONATOeMORRETES, 2007;ALVES etal., 2008; GOMES et al., 2009). O feixe vascular da nervura mediana é bicolateral, formando um arco com abertura voltada para a face adaxial, o que corrobora os resultados de Palhares (2003), Donato e Morretes (2007) e Gomes et al. (2009). Além disso, tais características são úteis para a distinção dos gêneros Siphoneugen e, Psidium e espécies de Eugenia (GOMES et al., 2009).

No mesofilo, a presença de fibras e da bainha vascular pode indicar participação nos processos de condução, ampliando, assim, o contato entre as células do mesofilo e do sistema vascular; a presença de parênquima clorofiliano paliçádico, com células grandes, alongadas perpendicularmente e unidas, também contribui para formar barreira de proteção contra a perda de água (DENGLER, 1994). Segundo esse autor, o alongamento perpendicular das células do parênquima paliçádico à custa do parênquima lacunoso é o que altera notavelmente a relação superfície/volume da folha e favorece a transferência perpendicular de carboidratos e nutrientes na folha.

A presença de idioblastos contendo drusas nas células do mesofilo são comuns nas células vegetais de vários órgãos e têm como principal função remover o excesso de cálcio do sistema (FAHN, 1990). Outras funções comumente associadas à presença desses cristais estão relacionadas com a defesa da planta contra herbivoria e estratégia de manutenção de nutrientes, como reserva de cálcio ou oxalato para a planta (VOLK et al., 2002). Adicionalmente, os cristais podem refletir uniformemente a radiação solar entre as células do mesofilo, devido às suas propriedades reflexivas (LARCHER, 2001).

Quanto ao pecíolo, destaca-se que o sistema de revestimento e de preenchimento são semelhantes aos encontrados por Palhares (2003) e Donato e Morretes (2007). Palhares (2003) encontrou, como resultado de seu trabalho com Eugenia dysenterica DC (Myrtaceae), feixe vascular composto por xilema organizado em colunas aparentemente separadas por um septo fibroso (fibras esclerenquimáticas) nas extremidades. Tais resultados corroboram as observações deste estudo. Além disso, o feixe vascular, associado às fibras esclerenquimáticas em forma de arco com extremidades curvas, confere maior resistência à estrutura, característica presente em outras espécies do gênero (HUSSIN et al., 1992; FONTENELLE et al., 1994; JORGE et al., 1994; HARON e MOORE, 1996).

Cabe ainda salientar a presença de ductos glandulares que percorrem toda a extensão do pecíolo, em continuidade com o limbo, podendo explicar a curvatura da folha, através da entrada e saída de água ao longo desses ductos, havendo, no entanto, a necessidade de mais estudos sobre esse assunto.

Por todas essas características mencionadas, pode-se afirmar que a espécie possui características que a tornam mais competitiva para sobreviver em ambientes sujeitos à restrição hídrica ou alta irradiância pois, ao movimentar sua folha em situações de longa estiagem, ela se expõe menos à luz e, consequentemente, perde menos água e consegue manter-se viva sem perder suas folhas, economizando energia e favorecendo a rápida recuperação fotossintética em resposta à hidratação.

Revista Árvore, Viçosa-MG, v.35, n.2, p.255-263, 2011 


\section{CONCLUSÃO}

Diante dos resultados, conclui-se que:

1. A folha de Eugenia glazioviana possui características de plantas de ambientes xéricos: cutícula espessa em ambas as superfícies, folha hipoestomática com muitos tricomas tectores na face abaxial. Essas são características esperadas em plantas como essa, estando presente em formações de Floresta Decidual, bem como Semidecidual, em bordas e áreas abertas, o que sugere especialização a ambientes com alta irradiância e, consequentemente, onde as plantas estão sujeitas a períodos intermitentes de déficit hídrico.

2. A característica marcante que pode ser exclusiva da espécie é a presença de ductos glandulares no pecíolo em continuidade com a lâmina foliar, que formam canais que contêm possivelmente substâncias osmorreguladoras, permitindo a movimentação da folha.

3. Necessidade de mais estudos que comprovem o papel desses ductos, bem como a natureza química das substâncias que eles armazenam.

\section{REFERÊNCIAS}

ALVES, E. S.; TRESMONDI, F.; LONGUI, E. L. Análise estrutural de folhas de Eugenia uniflora L. (Myrtaceae) coletadas em ambientes rural e urbano, SP, Brasil. Acta Botânica Brasilica, v.22, n.1, p.241-248, 2008.

CHARTZOULAKIS, K. et al. Water stress affects leaf anatomy, gas exchange, water relations and growth of two avocado cultivars. Scientia Horticulturae, v.95, n.1, p.39-50, 2002.

CHAVES FILHO, J. T.; STACCIARINI-SERAPHIN, E. Alteração no potencial osmótico e teor de carboidratos solúveis em plantas jovens de lobeira (Solanum lycocarpum St.-Hil.) em resposta ao estresse hídrico. Revista Brasileira de Botânica, v.24, n.2, p.199-204, 2001.

DENGLER, N. G. The influence of light on leaf development. In: IQBAL, M. (Ed.). Growth patterns in vascular plants. Oregon: Dioscorides Press, 1994.p.100-136.

DICKISON, W. C. Integrative plant anatomy. New York: Academic Press, 2000. 533p.

Revista Árvore, Viçosa-MG, v.35, n.2, p.255-263, 2011
DONATO, A. M.; MORRETES, B. L. Anatomia foliar de Eugenia brasiliensis Lam. (Myrtaceae) proveniente de áreas de restinga e de floresta. Revista Brasileira de Farmacognosia, v.17, n.3, p.426-443, 2007.

ELIAS, S. R. M. et al. Anatomia foliar em plantas jovens de Solanum lycocarpum A.St.-Hil. (Solanaceae). Revista Brasileira de Botânica, v.26, n.2, p.169-174, 2003.

FAHN, A. Plant anatomy. New York: Pergamon Press, 1990.

FONTENELLE, G.; COSTA, C.; MACHADO, R. Foliar anatomy and micromorphology of eleven species of Eugenia L. (Myrtaceae). Botanical Journal of the Linnean Society, v.115, p.111-133, 1994.

GOMES, S. M. et al. Anatomia foliar de espécies de Myrtaceae: contribuições à taxonomia e filogenia. Acta Botânica Brasilica, v.23, n.1, p.223-238, 2009.

GRIME, J. P.; MACKEY, J. M. I. The role of plasticity in resource capture by plants. Evolutionary Ecology, v.16, p.299-307, 2002.

HANBA, Y. T.; KOGAMI, H.; TERASHIMA, L. The effects of growth irradiance on leaf anatomy and photosynthesis in Acer species differing in light demand. Plant Cell and Enviroment, v.25, n.8, p.1021-1030, 2002.

HARON, N.; MOORE, D. The taxonomic significance of leaf micromorphology in the genus Eugenia L. (Myrtaceae). Botanical Journal of the Linnean Society, v.120, p.265-277, 1996.

HUSSIN, K.; CUTLER, D.; MOORE, D. Leaf anatomical studies of Eugenia L. (Myrtaceae) species from the Malay Peninsula. Botanical Journal of the Linnean Society, v.110, p.137-156, 1992.

IVANAUSKAS, M. N.; RODRIGUES, R. R. Floristíca e fitossociologia de remanescentes de Floresta Estacional Decidual em Piracicaba, São Paulo. Revista Brasileira de Botânica, v.23, n.3, p.291-304, 2000. 
JORGE, L. et al. Caracterização

farmacognóstica das folhas e frutos de Eugenia uniflora (Myrtaceae). Revista Lecta, v.12, n.2, p.103-120, 1994.

KARNOVSKY, M. J. A formaldehydeglutaraldehyde fixative of high osmolality for use in eletron microscopy. Journal of Cellular Biology, v.27, n.1, p.137-138, 1965.

KRAUS, J. E.; ARDUIN, M. Manual básico de métodos em morfologia vegetal. Seropédica: EDUR, 1997. 198p.

KUNDU, S. K.; TIGERSTEDT, P. M. A. Variation in net photosynthesis, stomatal characteristics, leaf area and whole plant phytomass production among ten provenances of neem (Azadirachta indica). Tree Physiology, n.19, p.47-52, 1998.

LAMBERS, H.; CHAPIN, F.S.; PONS, T.L. Plant physiological ecology. New York: SpringerVerlag. 1998. 540p.

LARCHER, W. Ecofisiologia vegetal. São Carlos: Rima, 2001. 531p.

LICHTENTHALER, H. K. Vegetation stress: an introduction to the stress concept in plants Journal Plant Physiology, v.148, n.1, p.4-14, 1996.

LIMA Jr., E. C. et al. Aspectos fisioanatômicos de plantas jovens de Cupania vernalis camb. submetidas a diferentes níveis de sombreamento. Revista Árvore, v.30, n.1, p.33-41, 2006.

MEnEZES, N. L. et al. (Eds.) Anatomia vegetal. Viçosa, MG: Universidade Federal de Viçosa, 2003. p.303-311.

PALHARES, D. Caracterização farmacognóstica das folhas de Eugenia dysenterica DC (Myrtaceae Jussieu). Revista Lecta, v.21, n.1/2, p.29-36, 2003.

PEREIRA, Z. V.; MEIRA, R. M. S. A.; AZEVEDO, A. A. Morfoanatomia foliar de Palicourea longepedunculata Gardiner (RUBIACEAE). Revista Árvore, v.27, n.6, p.759-767, 2003.
SAKAI, W. S. Simple method for different staining of parafin embedded plant material using toluidine blue O. Stain Technology, v.48, p.247-249, 1973.

SCHLUTER, U. et al. Photosyntetic performance of an Arabidopsis mutant with elevated stomatal density (sdd1-1) under different light regimes. Journal of Experimental Botany, v.54, n.383, p.867-874, 2003.

SILVA, L.A.; SCARIOT, A. Composição florística e estrutura da comunidade arbórea em uma floresta estacional decidual em afloramento calcáreo (Fazenda São José, São Domingos, GO, Bacia do Rio Paraná). Acta Botanica Brasilica, v.17, p.305-313, 2003.

TAIZ, L.; ZEIGER, E. Fisiologia vegetal. Porto Alegre: Artmed, 2004.p.449-484.

TURNER, N. C. Further progress in crop water relations. In: SPARKS, D.L.. (Ed.). Advances in agronomy. New York: Academic Press, 1997.p.293-337.

VERSLUES, P. E. et al. Methods and concepts in quantifying resistance to drought, salt and freezing, abiotic stresses that affect plant water status. The Plant Journal, v.45, p.523-539, 2006.

VIA, S. Adaptive phenotypic plasticity: target or byproduct of selection in a variable environment. The American Naturalist, v.142, p.352-365, 1993.

VIA, S. et al. Adaptive phenotypic plasticity: consensus and controversy. Trends in Ecology and Evolution, v.19, n.1, p.212-217, 1995.

VOLK, G. M. et al. The role of druse and raphide calcium oxalate crystals in tissue calcium regulation in Pistia stratiotes leaves. Plant Biology, v.4, p.34-45, 2002.

WERKER, E. Trichome diversity and development. In: HALLAHAN, D. L.; GRAY, J. C. (Eds.) Plant Trichomes. London: Academic Press, 2000. p.1-30 (Advances in Botanical Research, 31). 
